Chadwick et al divided a group of patients with supraspinal myoclonus into three categories. ${ }^{3}$ One group responded poorly to serotonergic drugs-namely, clonazepam and 5-hydroxytryptophan; a second group had proximal myoclonus, prominent spikes on the electroencephalogram, excellent response to serotonergic drugs, and physiological features suggesting that abnormal discharges originated in the brain-stem reticular formation (reticular reflex myoclonus). The third group showed mainly distal myoclonus, few sharp waves on the electroencephalogram, and only moderate response to serotonergic drugs; a cortical origin of the myoclonus was postulated for this group. Recently Chadwick and French 4 suggested that two uraemic patients whom they studied clinically had reticular reflex myoclonus.
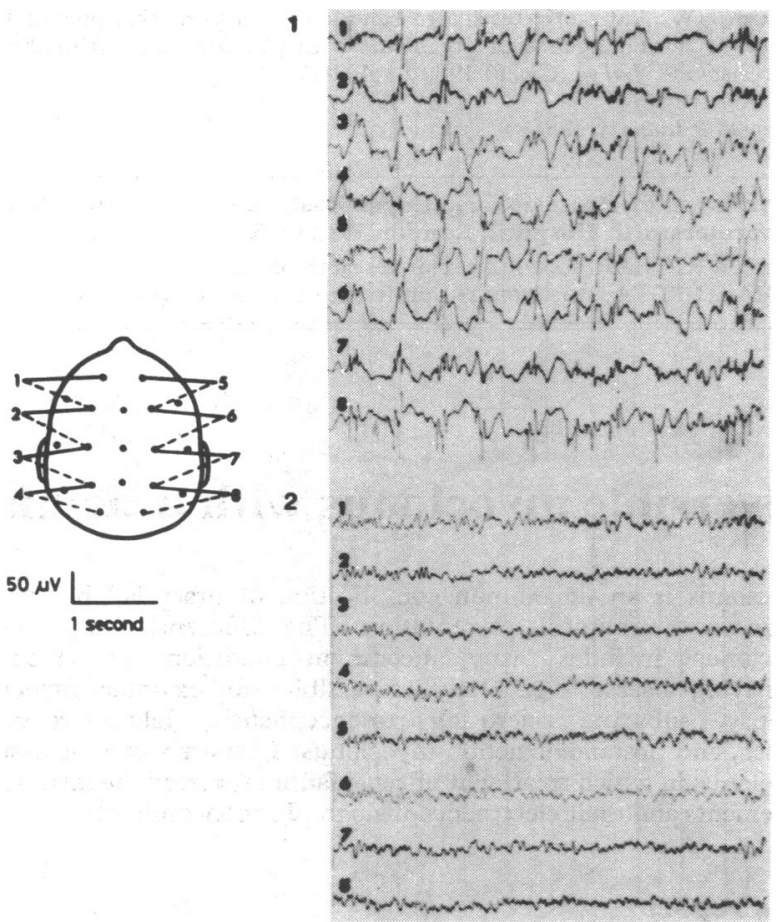

Top: electroencephalogram before peritoneal dialysis showing bilateral, synchronous spike discharges occurring irregularly and related temporally to the myoclonic jerks. Bottom: electroencephalogram recorded three days later, when myoclonus no longer occurred, showing no spike discharges, the only abnormality being a moderate diffuse excess of theta activity.

Electroencephalographic and other physiological data were unfortunately not available.

The bilaterally synchronous nature of the spike discharges in the present case suggests an abnormality arising in deep structures projecting to both hemispheres, and would support the view that a reversible biochemical insult to the brain-stem reticular formation may play a major part in the production of uraemic myoclonus.

I thank Dr D F Scott for his help and advice in the preparation of this report, and Drs A Ridley and F Marsh for their permission to publish this report of a patient under their care.

1 Tyler HR. Neurological disorders seen in renal failure. In: Vinken PJ, Bruyn GW, eds. Handbook of clinical neurology. Vol 27. Amsterdam: North Holland Publishing Co, 1976:321-48.

2 Swanson PD, Luttrell CN, Magladery JW. Myoclonus-a report of 67 cases and a review of the literature. Medicine (Baltimore) 1962;41: 339-56.

${ }^{3}$ Chadwick D, Hallett M, Harris R, Jenner P, Reynolds EH, Marsden CD.

Clinical, biochemical and physiological features distinguishing myoclonus responsive to 5-hydroxytryptophan, tryptophan with a monoamine oxidase inhibitor and clonazepam. Brain 1977;100:455-87.

${ }^{4}$ Chadwick D, French AT. Uraemic myoclonus: an example of reticular reflex myoclonus. F Neurol Neurosurg Psychiatry 1979;42:52-5.

(Accepted 20 fanuary 1981)

Section of Neurological Sciences, The London Hospital, London E1 1BB

RICHARD J STARK, MB, FRACP, neurological registrar

\section{Ruptured popliteal cyst and pyogenic arthritis}

Rupture of a popliteal cyst is well recognised, producing pain and swelling in the calf which may be mistaken for deep vein thrombosis. ${ }^{1}$ Though far more common in patients with established arthritis of the knee, particularly rheumatoid arthritis, rupture of a popliteal cyst has $\mathbb{\Phi}$ also been described in normal knees. ${ }^{2} I$ describe two patients in whom rupture of a popliteal cyst was the presenting sign of pyogenic arthritis 0 of the knee. Neither patient had rheumatoid arthritis.

\section{Case 1}

A 72-year-old woman in previous good health had sudden onset of pain and swelling of the right knee and calf shortly after walking to the shops. Pain and swelling increased over the next few days, and walking became 0 impossible. She had previously noticed a small swelling at the back of the knee but this had disappeared at the onset of pain. On admission she was apyrexial. The right knee and lower leg were grossly swollen, warm, and tender. There was no erythema or cellulitis and she was clinically euthyroid. $\vec{\omega}$ The left knee and general medical examination were normal, though she was overweight. Phenylbutazone had had no effect, and it was decided to aspirate the knee at the time of arthrography. Thick pus was aspirated from the knee, however, and arthrography was not performed. Culture grew Staphylococcus aureus. Results of other relevant investigations were: haemoglobin concen- ? tration $9.4 \mathrm{~g} / \mathrm{dl}$, white cell count $8.1 \times 10^{9} / 1$ ( $83 \%$ polymorphs), platelet count $625 \times 10^{2} / 1$, erythrocyte sedimentation rate $125 \mathrm{~mm}$ in first hour, blood urea concentration $16.5 \mathrm{mmol} / 1(99 \mathrm{mg} / 100 \mathrm{ml})$, normal electrolyte ? and plasma glucose values, negative RA latex test result, absent antinuclear $\overrightarrow{ }$ factor, and positive antibody titres against thyroid microsomes and thyro- $\vec{N}$ globulin. No crystals were found in the synovial fluid, and blood cultures were sterile. Chest radiograph was normal. Radiography showed normal hips but osteoarthritis of the knees, most distinct on the right.

After a long stay in hospital complicated by haematemesis and melaena, $D$ which required transfusion and may have been due to anti-inflammatory drugs (barium-meal findings were normal), she was left with stiffness of the right knee and needed a stick. There was no effusion and the calf swelling $\vec{\varphi}$ had subsided. Treatment of the septic arthritis consisted of intravenous $\propto$ antibiotics initially, arthrotomy and drainage of the right knee, and oral . antibiotics for five months. Blood urea concentration returned to normal, and erythrocyte sedimentation rate fell to $24 \mathrm{~mm}$ in first hour.

\section{Case 2}

An 80-year-old nun developed pain and swelling of the right knee which did not settle with anti-inflammatory drugs. Haemoglobin concentration was $\overline{0}$ $11.2 \mathrm{~g} / \mathrm{dl}$, white cell count $6.5 \times 10^{9} / 1(81 \%$ polymorphs), platelet count 3 normal, and erythrocyte sedimentation rate $77 \mathrm{~mm}$ in first hour. She had noticed a painless swelling at the back of the right knee a few weeks before, $\overline{0}$ but this was no longer palpable, and examination showed gross swelling of the right calf and ankle. The right knee was swollen, hot, and tender, with overlying erythema and she was unable to walk. In 1973 she had undergone anterior resection for carcinoma of the sigmoid colon with no evidence of metastases at operation or on follow-up. She had also been found to be hypothyroid two months before admission and was taking thyroxine. There was no other history of any joint problem.

On admission she was apyrexial and clinically euthyroid. Fluid aspirated from the right knee contained thick yellow pus, which on culture grew 0 Escherichia coli. Other investigations showed normal urea and electrolyte $\supset$ values, normal plasma glucose concentration, negative RA latex test result, $\mathbb{N}$ strongly positive thyroid antibodies, absent antinuclear factor, absence of $D$ crystals in the synovial fluid, sterile blood cultures, and a normal chest $\frac{D}{2}$ radiograph. Radiography of the knees showed osteoarthritis and osteoporosis.

She was started on amoxycillin by mouth, and $500 \mathrm{mg}$ of this drug was $\mathrm{N}$ injected into the right knee at weekly intervals for three weeks after aspiration $\omega$ of fluid. The third aspirate was sterile. Gradual mobilisation followed several 0 weeks of bed rest, and when discharged she could walk slowly using a frame. The swelling of the right knee and calf gradually subsided. Oral antibiotics were continued for a further three months with a gradual fall in the erythrocyte sedimentation rate.

\section{Comment}

A ruptured popliteal cyst as the presenting feature of pyogenic $\stackrel{\mathbb{Q}}{\circ}$ arthritis which occurred shortly after a total hip arthroplasty on the opposite side was recently reported in a patient with rheumatoid $\delta$ arthritis. ${ }^{3}$ My two patients had underlying osteoarthritis, not surprising in view of their ages, and there were no special features to account for any increased susceptibility to infection. Both had antibodies to thyroid microsomes and thyroglobulin but were euthyroid at the 
onset of symptoms. Rupture of a popliteal cyst and acute rupture of the knee may occur in rheumatoid arthritis, and both may produce identical signs and symptoms. ${ }^{4}$ In these patients the presence of a popliteal cyst noticed by the patients themselves and its subsequent disappearance suggests that the calf swelling was due to leakage from the cyst rather than rupture of the joint. What is not clear is why there was an associated pyogenic arthritis. Did the infection in the knee occur before the rupture and actually cause the cyst to rupture by retrograde spread of infected synovial fluid, or was the synovial fluid completely sterile at the time of rupture only to become subsequently infected perhaps in the presence of a transient bacteraemia? Aspiration of synovial fluid from the knee for analysis and culture is therefore advisable in any patient presenting with a ruptured popliteal cyst, particularly the elderly.

'Good AE. Rheumatoid arthritis, Baker's cyst and thrombophlebitis Arthritis Rheum 1964; 7:56-64.

2 Macfarlane DG, Bacon PA. Popliteal cyst rupture in normal knee joints. Br Med F 1980;281:1203-4.

${ }^{3}$ Stewart IM, Swinson DR, Hardinge K. Pyogenic arthritis presenting as a ruptured popliteal cyst. Ann Rheum Dis 1979;38:181-2.

4 Jayson MIV, Swannell AJ, Kirk JA, Dixon AStJ. Acute joint rupture. Annals of Physical Medicine 1969-70;10:175-9.

(Accepted 20 fanuary 1981)

Department of Rheumatology, Worthing Hospital, Worthing BN11 2DH

A J RICHARDS, MRCP, DPHYSMED, consultant rheumatologist

\section{Acquired alpha $a_{2}$ antiplasmin deficiency in glomerular proteinuria}

Antithrombin III deficiency has been described in patients with proteinuria, where it is thought to be due to glomerular leak. ${ }^{1}$ Such deficiency has been proposed as an important factor in the aetiology of the tendency for venous thrombosis in these patients. The major plasmin inhibitor, $\alpha_{2}$-antiplasmin, has a molecular weight of $65-70 \times 10^{3}$ and might also be expected to leak through damaged glomeruli. We have therefore measures $\alpha_{2}$-antiplasmin concentrations in the plasma of 20 patients with the nephrotic syndrome.

\section{Patients, methods, and results}

$\alpha_{2}$-Antiplasmin concentrations were measured in the plasma of 20 patients with moderate to severe glomerular proteinuria confirmed by renal biopsy and in nine normal controls. Assay was performed by immunoelectrophoresis, as described. ${ }^{2}$ Simultaneous urine samples were obtained from eight of these patients and five controls and assay of unconcentrated urine and diluted plasma performed in parallel.

$\alpha_{2}$-Antiplasmin concentrations in 20 patients with nephrotic syndrome and nine controls

\begin{tabular}{|c|c|c|c|c|c|}
\hline \multicolumn{3}{|c|}{ Patients } & \multicolumn{3}{|c|}{ Controls } \\
\hline Subject & $\underset{\left({ }^{\prime \prime} .1\right)}{\text { Plasma }}$ & Urine & Subject & $\underset{\left({ }^{\prime \prime}\right.}{\left.N_{0}\right)}$ & Urine \\
\hline $\begin{array}{r}1 \\
2 \\
3 \\
4 \\
5 \\
6 \\
7 \\
8 \\
9 \\
10 \\
11 \\
12 \\
13 \\
14 \\
15 \\
16 \\
17 \\
18 \\
19 \\
20\end{array}$ & $\begin{array}{r}90 \\
91 \\
25 \\
84 \\
46 \\
43 \\
37 \\
55 \\
69 \\
102 \\
66 \\
92 \\
44 \\
127 \\
66 \\
84 \\
70 \\
100 \\
96 \\
64\end{array}$ & $\begin{array}{l}\text { Trace } \\
\text { Nil } \\
\text { Trace } \\
\text { Trace } \\
\text { Trace } \\
\text { Trace } \\
\text { Trace } \\
11 \text { "." }\end{array}$ & $\begin{array}{l}1 \\
2 \\
3 \\
4 \\
5 \\
6 \\
7 \\
8 \\
9\end{array}$ & $\begin{array}{r}115 \\
105 \\
115 \\
83 \\
88 \\
109 \\
125 \\
83 \\
95\end{array}$ & $\begin{array}{l}\mathrm{Nil} \\
\mathrm{Nil} \\
\mathrm{Nil} \\
\mathrm{Nil} \\
\mathrm{Nil}\end{array}$ \\
\hline ean : SD & $72 \cdot 6: 26 \cdot 0$ & & & $02 \cdot 0:$ & \\
\hline
\end{tabular}

*Unpaire d $t$ test : $\mathrm{p}<0.01$
The table gives the results. Significantly lower $\alpha_{2}$-antiplasmin values were found in patients with the nephrotic syndrome, 11 out of 20 showing values below the normal range ( $p<0.01$; unpaired $t$ test). The unconcentrated urine showed detectable $\alpha_{2}$-antiplasmin antigen in seven of the eight patients studied. In one patient the concentration was $11 \%$ of the plasma value, though he maintained a normal plasma value.

\section{Comment}

$\alpha_{2}$-Antiplasmin and $\alpha_{2}$-macroglobulin are the two main inhibitors of plasmin. Of these, $\alpha_{2}$-antiplasmin is recognised as the major inhibitor of plasmin. Its action is very rapid, so that $\alpha_{2}$-macroglobulin inhibits only when large amounts of plasmin are generated. ${ }^{3}$ Concentrations of $\alpha_{2}$-macroglobulin may be raised in the nephrotic syndrome. ${ }^{4}$ In contrast, our study shows that $\alpha_{2}$-antiplasmin may be deficient and that the low values seen attributable at least in part to renal loss. There are three possible consequences of this deficiency of $\alpha_{2}$-antiplasmin. Firstly, the deficiency of the major, fast-acting antiplasmin may tend to counterbalance any predisposition to thrombosis caused by deficiency of antithrombin III. Secondly, deficiency of $\alpha_{2}$-antiplasmin may contribute to the increase in glomular fibrinolytic activity observed in patients with glomerulonephritis $^{5}$ and contribute to the removal of intraglomerular fibrin deposits. Thirdly, the presence of such a potent plasmin inhibitor in urine may inhibit fibrinolysis in the urinary tract and may explain the observation that fibrinogen may be present intact in the urine in the nephrotic syndrome.

Requests for reprints should be sent to Dr D A Taberner.

1 Thaler E, Balzar E, Kopsa H, Pinggera WF. Acquired antithrombin III deficiency in patients with glomerular proteinuria. Haemostasis 1978 ; 7:257-72.

2 Taberner DA, Poller L, Burslem RW. Antiplasmin concentrations after surgery: failure of alpha antiplasmin to rise in patients with venous thrombosis. Br Med $\mathcal{F} 1979 ; \mathrm{i}: 1122-3$.

${ }^{3}$ Aoki N, Moroi M, Matsuda M, et al. The behaviour of alpha- ${ }_{2}$-plasmin inhibitor in fibrinolytic states. 7 Clin Invest 1977;60:361-71.

${ }^{4}$ Horne CHW, Briggs JD, Howie PW, Kennedy AC. Serum $\alpha_{2}$-macroglobulins in renal disease and pre-eclampsia. F Clin Pathol 1972;25 590-3.

${ }^{5}$ Ekberg M, Pandolfi $M$. Origin of urinary fibrin/fibrinogen degradation products in glomerulonephritis. Br Med f 1975;ii:17-9.

(Accepted 23 fanuary 1981)

Withington Hospital, University Hospital of South Manchester, Manchester M20 8LR

D A TABERNER, MRCP, MRCPATH, consultant haematologist

A J RALSTON, MB, FRCP, consultant physician

P ACKRILL, MB, FRCP, consultant physician

\section{Hydralazine-induced necrotising vasculitis}

The association of the "lupus" syndrome with hydralazine is wel" known but there have been only two reported cases of cutaneous vasculitis related to hydralazine. ${ }^{1}$ Both of these cases were mild. We report a third case, with severe and widespread vasculitic lesions, associated with a hydralazine dose of only $75 \mathrm{mg} /$ day.

\section{Case report}

A 69-year-old woman began treatment with hydralazine $(75 \mathrm{mg} /$ day) in 1972 for resistant hypertension. At the time she was also taking propranolo and hydrochlorothiazide. She remained well until December 1979, when she was admitted to hospital with a temperature of $38^{\circ} \mathrm{C}$ and multiple $2 \times 2 \mathrm{~cm}$ haemorrhagic blisters on her lower legs (figure). She gave a two-week history of malaise and muscle pains. Shortly after admission additiona lesions appeared on arms, trunk, nasal septum, and uvula. Hydralazine was stopped and no further blisters developed, but when several of the lesions began to ulcerate she was given a course of prednisolone and cyclophosphamide. All the affected areas gradually healed, but the most severely ulcerated lesions required skin grafting.

Results of investigations included erythrocyte sedimentation rate $130 \mathrm{~mm}$ in first hour, haemoglobin concentration $10.9 \mathrm{~g} / \mathrm{dl}$, white cell count $14.8 \%$ $10^{9} / 1\left(14800 / \mathrm{mm}^{3} ; 84 \%\right.$ polymorphs $)$, and normal routine biochemical 